\title{
O JORNAL COMO FONTE LITERÁRIA NA VIRADA DO SÉCULO XIX PARA O XX: O CASO DE SÃO PAULO
}

\section{THE NEUSPAPER AS LITERARY SOURCE IN THE TURN OF THE CENTURY XIX TO XX: THE CASE OF SÃO PAULO}

\section{Rafael Rodrico FerreiRa*}

RESUMO: O seguinte trabalho pretende reivindicar a importância do jornal para os estudos literários da Primeira República (1889-1930), na medida em que expõe particularidades do caso paulista, bem como disserta acerca de possíveis problemas de parcela significativa da crítica literária que, desatenta aos compartilhamentos entre literatura e jornalismo, ofusca, consequentemente, processos indispensáveis para a compreensão da constituição das letras brasileiras.

PALAVRAS-CHAVE: literatura, jornalismo, imprensa, modernidade, São Paulo.

ABSTRACT: The following work intends to claim the importance of the newspaper for the literary studies of the First Republic (1889-1930), as it exposes peculiarities of São Paulo context, as well as discusses possible problems of a significant part of literary criticism that, inattentive to the shares between literature and journalism, hides, consequently, processes that are indispensable for the understanding of the constitution of brazilian literature.

KEYWORDS: literature, journalism, press, modernity, São Paulo.

\footnotetext{
* Doutorando em Literatura Brasileira na Faculdade de Filosofia, Letras e Ciências Humanas da Universidade de São Paulo (FFLCH/USP).
} 


\section{Considerações gerais}

Antes de abordar as relações entre literatura e jornalismo, é importante registrar brevemente que o jornal, e a imprensa em geral, utilizado como fonte de pesquisa histórica, ganhou considerável terreno no Brasil a partir dos anos 1970, sob influência exercida pela escola dos Annales, pós 1968, tornando-se recorrente nos estudos ligados a este campo do conhecimento, agora assumidamente interdisciplinar. Ainda que exista, justificadamente, uma larga diferença entre jornalismo e história, essas duas áreas são, de modo geral, próximas, pois lidam com uma tarefa de apreensão e restituição interpretativa do real, divergindo entre si, evidentemente, em seus métodos e abordagens temporais, e entre ambas e a literatura, pela própria natureza e intencionalidade de cada área. Podemos dizer que, em vista do que foi no passado, a interdependência entre as duas áreas, jornalismo e história, é um fato hoje consumado, desde que haja determinada acuidade metodológica, assim como uma abalizada utilização do jornal enquanto documento-fonte por parte do historiador. Em outras palavras, que se depurem as direções ideológicas que influenciam diretamente as formulações discursivas dos jornais utilizados para pesquisa, dentro das quais as interpretações dos fatos devem ser evidenciadas enquanto tais, pois, sabe-se, que nem imprensa e, tampouco, a historiografia, podem ser sinônimos de verdade factual irrefletida, apesar da pretensão em alguns casos.

Já no que diz respeito ao jornal enquanto fonte literária, evidenciadas suas trajetórias interdependentes no Brasil, é, ainda assim, pouco explorado, ao menos do ponto de vista do crítico-historiador-estudioso da literatura. Em geral, filólogos, críticos textuais e genéticos ou historiadores da literatura - ou a quem cabe o importante trabalho, dentre outros, de amplificação de fontes literárias, mais do que fundamental, ainda que exíguo entre nós - atuam, em geral, com olhos restritos ao livro (ou a uma época específica entendida como consagrada, como veremos adiante), com exceção, talvez, da crítica genética, de modo que esta tende a acessar os jornais, e outras fontes diversas, muito embora, ainda assim, na maior parte das vezes, em busca de reconstituição dos caminhos de determinado escritor que o levaram ao livro publicado ou que ficou por publicar. Ao fim e ao cabo, o livro é, majoritariamente, objeto uno do estudioso de literatura. Obviamente a ligação entre literatura e livro não deve, absolutamente, ser prejudicada ou substituída, nem mesmo suprimida dos estudos de literatura em 
geral, quer do período aqui em questão ou qualquer outro. Não é disso que se trata. Contudo, para uma sondagem mais ampla da época, devemos estar atentos a alguns dados, a nosso ver, incontornáveis.

Em uma análise mais detida do período em questão é possível perceber que esta escolha de fonte, qual seja o livro, não deve ser exclusiva para o estudioso, de sorte que qualquer operação analítica neste sentido se mostra ineficaz por si só para representar, ou melhor, sintetizar as produções, mentalidades e leituras literárias da época. Isto se dá porque a publicação em livro da literatura no período é inexpressiva e daí sua incapacidade de ser instrumento único de reconstituição literária, ao passo que a produção periódica (jornais e revistas), em ascensão perene desde então, não sem altos e baixos, ganha relevo surpreendente em termos de comparação.

A primeira década da República foi, como sabemos, convulsionada por diversos atritos políticos e sociais que afetaram, à queima roupa, a indústria livresca brasileira, provocando uma defasagem particular no setor:

As mortes de Baptieste Garnier e dos irmãos Laemmert - os três homens que haviam dominado por tanto tempo o mercado livreiro no Brasil - contribuíram para esse mal-estar mas a causa subjacente era o estado conturbado de todo o corpo político que se seguiu ao fim do Império em 1889. (HALLEWELL, 2012, p. 280).

As balizas políticas articuladas à queda do comércio livreiro de que fala Hallewell podem ser pensadas em diversas chaves. Destaco dentre muitas apenas uma, a qual será essencial para pensarmos o caso de São Paulo mais à frente. Com a proclamação da República, impulsionada especialmente pela classe militar, os donos do poder ${ }^{1}$ passam a ser a oligarquia cafeeira, em particular paulista, se pensarmos os limites da contribuição civil com a qual contou a efetivação da queda do Império. Em detrimento, portanto, de uma elite aristocrática açucareira nordestina, a qual prezava por certa diligência intelectual, sob vultos de nobreza, predomina, a partir de então, os fazendeiros de café, que, por seu turno, "julgavam a riqueza (não importando sua origem) muito mais importante do que o berço, a educação ou a cultura" (ibid., p. 283) em um notável raciocínio

1 Referência às obras de Raymundo Faoro. 
arrivista, muito sintomático para o desenvolvimento intelectual. Ademais, "uma fase de repouso, de empobrecimento, de esterilidade das nossas letras" (SODRÉ, 1983, p. 288), catalisada pela mentalidade oligárquica, é justificada também por um crescimento sistemático da censura por meio da qual tanto os livros quanto a imprensa periódica foram solapados. O controle exercido pelos republicanos detentores do poder é um evidente contrassenso, dentre vários outros que presidiram o cerceamento da liberdade, já que o próprio ideário republicano foi em grande escala propalado constitutivamente pelos jornais (MARTINS, 2011, p 73).

Pelos relatos dos próprios escritores, submetidos a todo esse imbróglio, vejamos, então, alguns depoimentos de quem cavou um lugar nas letras brasileiras neste período de distúrbios generalizados. O Momento literário de João do Rio, publicado na Gazeta de Notícias em 1905 e dois anos depois pela editora Garnier, permite-nos revisitar a atmosfera intelectual que refutava ou referendava as convergências atuantes entre jornalismo e literatura e, por conseguinte, jornalista e literato ou, ainda, jornal e livro. Nesta obra de entrevistas, as vozes alternaram para um ou outro lado de modo mais ou menos uniforme. Contudo, o que fica destacado é como o jornal parecia exercer forte presença entre os literatos, axiomática tanto nas falas daqueles que apoiavam as interlocuções entre as duas instâncias quanto dos que as contestavam. Olavo Bilac, o primeiro na sequência de entrevistados, e jornalista vivaz, afirma:

O jornalismo é para todo o escritor brasileiro um grande bem. É mesmo o único meio do escritor se fazer ler. O meio de ação nos falharia absolutamente se não fosse o jornal porque o livro ainda não é coisa que se compre no Brasil como uma necessidade. (BILAC, apud RIO, 1994, p. 18).

A todo tempo, no decorrer da entrevista, Bilac chama a atenção para a falta de instrução da sociedade brasileira, acusando o analfabetismo como sendo o principal problema por enfrentar a qualquer custo. No excerto, é interessante notar que o jornal, segundo o escritor, é "o único meio do escritor se fazer ler". Em que pese o analfabetismo, infere-se pelo trecho que através do jornal o escritor é lido em contraposição ao livro. Esta afirmação, encontrada em outros relatos colhidos por João do Rio, elucida como pano de fundo no mínimo duas questões fundamentais: a realização do escritor ao ser lido e o acesso mais democrático da população leitora, ainda que exígua e burguesa por excelência. 
Em uma linha de raciocínio similar, atacando a falta de instrução dos brasileiros, Medeiros de Albuquerque avança o pensamento e ressalta a importância do jornal como formador de público leitor e peça fundamental de transição para o livro, em um pensamento que relaciona mais intrinsecamente as duas áreas:

Não é verdade que o jornalismo prejudique em nada a nossa literatura. $\mathrm{O}$ que a prejudica é a falta de instrução. Sem público que leia, a vida literária é impossível. O jornal faz até a preparação desse público. Habitua alguns milhares de pessoas a uma leitura quotidiana de alguns minutos, dando-lhes amostras de todos os gêneros. Os que têm gosto e tempo começam por aí e passam para os livros. Mas o jornal é o indicador. Em nenhum país de grande literatura deixa de haver grande jornalismo. Sem este, aquela é impossível. Os que atacam a imprensa o que deviam fazer era atacar a falta de instrução. (MEDEIROS E ALBUQUERQUE, apud RIO, 1994, p. 76).

Se por um lado, pois, o jornal atua como formação de público leitor em um país cuja taxa de analfabetos impressiona (beirava os $70 \%$ da população), por outro auxilia no desenvolvimento, sobrevivência, reconhecimento e formação literária do próprio escritor que dele faz uso. Esta concepção é crucial para pensarmos, por exemplo, como o jornalismo pode ser tomado também como um suporte no qual o escritor viabiliza e testa seus direcionamentos estéticos, praticando sua escrita, o que pode fundamentar até mesmo a particular veia heterogênea, do ponto de vista formal, temático ou político, que caracteriza as produções literárias, motivo este, aliás, gerador de distanciamento de parcela significativa da crítica literária brasileira frente ao período, sobre a qual predomina um olhar unificador de estéticas e discursos (trataremos especificamente desta questão mais adiante). Vejamos o depoimento de Silvio Romero:

É no jornal que têm todos estreado os seus talentos; nele é que têm todos polido a linguagem, aprendido a arte da palavra escrita; dele é que muitos têm vivido ou vivem ainda; por ele, o que mais vale, é que todos se têm feito conhecer, e, o que é tudo, poderia ser mais se houvesse um acordo e junção de forças [...]. (ROMERO, apud RIO, 1994, p. 50). 
Já numa via de leitura macroscópica, Nestor Vitor reclama a falta de mecanismos institucionais capazes de fomentar a literatura de modo assertivo:

Terminando, sobre a questão de saber-se se o jornalismo é um bom ou mau fator para a arte literária, direi que se ele não existisse, se a evolução das coisas já tivesse podido eliminá-lo, substituindo-o por instituição melhor, seria bem bom para a arte literária. Mas como isso ainda não se realizou, e pelo contrário, o jornalismo resiste de cada vez mais vivaz, parece-me que hoje ela não o pode dispensar (NESTOR VITOR, apud RIO, 1994, p. 114).

No depoimento, a inevitabilidade do jornal para a consolidação da literatura, o qual não foi superado por "instituição melhor", é fundamental para refletirmos, inclusive, sobre o processo de autonomização literária pelo qual passou não somente o Brasil, mas toda a América Latina. Diferentemente do que ocorreu na Europa, a precária autonomia literária latino-americana e sua consolidação relativa enquanto campo específico, dada pelo insuficiente préstimo institucional, deu-se por meio do jornal, como esclarece Julio Ramos:

El periódico fue una condición de posibilidad de la modernización literaria, aunque también materializaba los límites de la autonomía. De ahí que el periódico finisecular (...) sea un lugar privilegiado para estudiar las condiciones de la modernización literaria, no sólo por su relación positiva con los "nuevos" escritores, que allí encontraron un lugar alternativo a las instituciones tradicionales, así como un medio de contacto y formación de un nuevo público; es un objeto privilegiado porque a la vez condensa las aporías irreductibles de la voluntad autonómica en América Latina. (RAMOS, 2009, p. 198).

A angústia vivenciada pelos escritores que não viam meios de divulgação literária pode ser interpretada, aliás, como uma grande aporia da época, em torno da qual a atividade jornalística, para grande parcela dos escritores, emergia como circunstância amenizadora de frustrações. Um caso ilustrativo neste sentido é o do poeta Augusto dos Anjos cujo único livro, lançado em 1912, foi quase que integralmente publicado em jornais paraibanos desde o início do século XX. Um dos motivos da atmosfera melancólica que pairava em torno de toda a produção do escritor, até mesmo de sua acanhada, mas importante cronística, foi, 
para Órris Soares, justamente as obstruções de ordem estrutural que minavam "o homem de pensamento", pois havia de se resignar a um "meio ainda longe de assimilar os frutos das poderosas civilizações" (2004, p. 72).

Em suma, a literatura, se pensada em contato contínuo com o jornal, passa por grande revolução em todas as suas atribuições: da formação quer do público leitor, carente de instrução, ou, ainda, de seu câmbio de hábito de leitura, mais corriqueiro e generalizado, quer do escritor em seus anseios e experimentações literários, descobrindo seus caminhos, acrescidos pelos impasses quanto à subsistência por meio das letras profissionais; da modernização literária, incorporada e incorporadora dos índices da modernidade à sua consolidação enquanto campo particularmente emergente.

\section{Considerações sobre o contexto cultural da São Paulo republicana}

O estabelecimento da República converge com a agenda neocolonial dispensada pelas potências europeias sobre os países da África e da Ásia. Sem entrar nos muitos detalhes que esse compasso pode suscitar, ressaltemos a presença do pensamento positivista, de tendência francesa especialmente, com o qual a República brasileira se articula em oposição à Monarquia. Havia, portanto, colada à ideia republicana o triunfo da ciência, do progresso e da concepção de modernidade, no que esse termo tem de mais geral. Daí podemos inferir que as instituições, regidas agora por um Estado e não mais por um rei, passaram a se enrijecer e tornaram-se ainda mais capazes de atuar de maneira a regular a razão, a circulação e os costumes e modos da população em geral. Tenta-se, assim, romper com qualquer ideia que remeta, seja política, econômica ou culturalmente a um passado colonial (SEVCENKO, 1983, p. 36-94). Todavia, neste período de transição política brusca pelo qual passa todo o país, São Paulo, por sua vez, guarda algumas particularidades importantes de serem atravessadas. Tendo em mente todo o contexto explicitado brevemente acima, algumas contradições merecem relevo para nossa argumentação.

A primeira delas é a evolução do jornal frente à falta de desenvolvimento de uma política econômica categoricamente industrial. Isto é, não houve uma política de crescimento manufatureiro direcionada em paralelo ao avanço do jornal em um primeiro momento. O que para um historiador marxista como 
Nelson Werneck Sodré, a quem o despontamento da imprensa brasileira está sempre intrinsecamente atado à expansão capitalista ${ }^{2}$, configura-se, à primeira vista, como uma "contradição" (1983, p. 276). Mesmo na primeira década da República, período de notável instabilidade, os jornais paulistas aparecem aos montes e com distintas origens, em oposição aos livros literários, escassos, por seu lado. Lembramos que neste momento o programa político-econômico brasileiro está reduzido à prática de exportação do café (e não a uma evolução industrial propriamente, característica de um sistema capitalista modernizado) com o qual São Paulo, um dos principais polos cafeicultores, se beneficiará consideravelmente antes mesmo da institucionalização da chamada "política dos governadores" instaurada por Campos Sales quando da sua passagem de presidente (governador) paulista à presidente da República em 1898, acentuando uma política de cunho agroexportador. Isto porque a constituição instaurada assegurava, em sua política de exportação e importação, os bônus do Estado produtor para si unicamente. A euforia em torno dessa estrutura pré-capitalista de monocultura tornou possível, inclusive, algumas tentativas, ainda que fracassadas, de movimentação de capital especulativo em bolsas de valores, chamadas de encilhamento (SAES, 2004, p. 220). Assim, grosso modo, com a constituição favorável e a "política dos governadores" institucionalizada mais adiante, São Paulo criou condições privilegiadas de acúmulo de capital, facilitando a vitalidade da imprensa periódica no Estado. Com ativa vida econômica, São Paulo passa a receber grande contingente de migrantes, sobretudo os do Nordeste fugidos da seca, e de imigrantes, advindos da Europa, em especial italianos e espanhóis. O massivo e diverso crescimento populacional, em consonância com a concentração de capital proveniente do café, permite a São Paulo impulsionar progressivamente sua imprensa (HALEWELL, 2012, p. 99). Nesse sentido, a imprensa paulista se diversifica etnicamente com a fundação de jornais das colônias italianas, espanholas, alemãs, japonesas etc. Destaquemos a imprensa operária, que, nascida "no bojo do desenvolvimento industrial, fruto da necessidade de defesa dos interesses dos trabalhadores frente aos padrões de exploração imperantes" (COHEN, 2011, p. 120), também reproduziam em suas tiragens literatura

2 José Marques de Melo, em seu livro Sociologia da imprensa brasileira: a implantação, relativiza a visão, tomada como unilateralmente economicista, de Sodré no que toca ao atraso do estabelecimento da imprensa brasileira em comparação com o restante da América Latina. 
de cunho político e social. A literatura anarquista da época, por exemplo, pesquisada em diversos trabalhos por críticos como Francisco Foot Hardman e Antonio Arnoni Prado, também encontrava no jornal uma forma de divulgação ${ }^{3}$, além de instrumento comparável ou superior aos sindicatos em termos de possibilidade de organização e difusão (FAUSTO, 2016, p. 112). Aliás, pontos de encontro e convívio, as redações de jornais reuniam escritores que ali mesmo debatiam, expunham e conjecturavam os rumos da literatura. Um dos vários exemplos dessa prática é a reunião dos escritores em torno da leitura da peça Leur ame, escrita em francês por Oswald de Andrade e Guilherme de Almeida, nas redações do jornal O Estado de São Paulo em 1916.

Já na virada do século, o jornalismo assume sua feição empresarial de modo mais deliberado, mesmo que sob um domínio político de mentalidades e ações pré-capitalista, no sentido mais estrito do termo. É preciso registrar, porém, que o jornal da segunda metade do século XIX, bem como a história, também foi alvo do incisivo cientificismo e, em vista disso, reivindicou para si a capacidade de mapear e organizar, munido da verdade incontestável, os acontecimentos e fatos da realidade presente, visão dominante nos dias atuais. O resultado é certo acanhamento da disposição literária no jornal, muito embora a presença da literatura, em folhetins, inclusive, e escritores em suas redações não tenham, ainda assim, perdido lugar relevante. Exatamente neste momento de recrudescimento do noticioso, influenciado especialmente pela linha americana de jornalismo (industrial-empresarial) em oposição à francesa, mais beletrista, e presunção da representação fidedigna do acontecimento é que se consolidam, nas bases do jornalismo moderno, figuras, também modernas, como o cronista e o repórter, os quais tensionam, do ponto de vista estilístico, jornalismo e literatura, gerando, assim, produções as mais diversas. Tais expressões literárias são identificáveis não somente naquelas encontradas nos jornais necessariamente. A influência do estilo jornalístico é manifesta também em livros, seja pela compilação da produção publicada em jornais, como o best-seller Urupês (1918) de Monteiro Lobato ou Os Caboclos (1920) de Valdomiro Silveira, seja pela clara incorporação

3 Destaco dois escritores santistas advindos das classes trabalhadoras e que fizeram sua vida literária em larga medida pelos jornais e revistas de grande e pequena circulação, atuando tanto na imprensa operária quanto na comercial: Afonso Schmidt (1890-1964) e Sylvio Floreal (18931928). 
das crônicas de costume e relatos sobre a vida urbana paulista, como em todos os livros do esquecido e mais produtivo romancista da época, José Agudo ${ }^{4}, \mathrm{Ma}$ dame Pommery (1919) de Hilário Tácito e até mesmo em Os Condenados (1922) e Serafim Ponte Grande (publicado em 1933, mas gestado nos anos de 1920), de Oswald de Andrade.

Nesse sentido, o contexto que agrupava mentalidades discrepantes e complementares, permeado por uma imprensa igualmente plural, diversifica o fazer literário do ponto de vista formal, temático e político. Ademais, esta parecer ser a condição para que, apesar da censura que marcou os primórdios da República, de que falamos mais acima, as expressões literárias paulistas sejam menos enraizadas, se compararmos com as da capital Rio de Janeiro, o que não significa dizer que gozavam de libertada de incondicional.

Como se sabe, cada uma das regiões brasileiras sofreu, a seu modo, os impactos bruscos dos processos de modernização e metropolização da virada do século XIX para o XX, mesmo que em doses desproporcionais. Muitos recortes são possíveis no intento de discriminar a formação de cada localidade, porém um, de caráter mais sociológico, parece favorecer às indicações que pretendemos aqui, apontando as particularidades da produção cultural em São Paulo. José Murilo de Carvalho, ao fazer um movimento comparativo com a então capital federal, pensando em especial o período em questão, recobra uma terminologia pertinente para se pensar as expressões culturais paulistas: Rio de Janeiro, como cidade "ortogenética", e São Paulo, como cidade "heterogenética" (CARVALHO, 1988, p.14).

Logo, na capital, e justamente por esta idiossincrasia, as demandas de cunho administrativo, de expressão máxima da imagem e legitimidade nacionais, tanto para o interior do país quanto para o exterior, e de seu passado colonial e escravista em perene negação conflituosa, fazia da cidade uma constante tentativa de equiparação a todo custo com o imaginário de civilização, eurocêntrico obviamente. Uma cidade política, antes de qualquer coisa. São Paulo, por seu turno, era, em certo sentido, mais livre das amarras institucionais e políticas, embora

4 Ver "Aventuras e desventuras de José Agudo, um cronista da Pauliceia na belle époque", de Elias Thomé Saliba, texto publicado na Revista USP, 2004. 
não completamente, da promoção da identidade nacional ${ }^{5}$, na medida em que se constituía mais próxima de uma cidade de produção, burguesa e imigrante. Uma cidade econômica, sobretudo. Os traços apresentados sumariamente aqui reservam para uma cidade "heterogenética", como São Paulo, segundo o crítico, um ambiente com "maior grau de liberdade de criação" (ibid., p.15), atributo sugestivo para pensar o mosaico artístico da cidade. Não obstante, a atuação da Academia Brasileira de Letras no sentido de regular as manifestações literárias era, principalmente no Rio de Janeiro, presença massiva desde o fim do século XIX (1897). Ao passo que, em São Paulo, a Academia Paulista de Letras, por exemplo, fundada somente em 1909, atuou, nos anos que se seguiram, com diminuta ou nenhuma influência no sentido de regulação da escrita literária produzida na cidade.

A importância de se apreender os caminhos que levaram São Paulo a desenvolver de modo particular o setor industrial, além de mapear a diversidade populacional, discursiva e política vigente, para as quais o jornal serviu de base, decorre do fato de que também a literatura, ou melhor, as direções estéticas como um todo, emana de modo essencialmente heterogêneo, gerando grande simultaneidade artística, perceptível, no caso das letras, pelo avanço da imprensa, sem a qual, não é possível acessar o quadro intelectual da época à saciedade

\section{Considerações finais: crítica literária e obstáculos de apreensão do jornal en- quanto fonte no Brasil.}

Se pensarmos nos modos como a crítica literária majoritária contornou o período que antecedeu o ano de 1922 no Brasil, notaremos facilmente que definições como "pré-modernismo" e "pós-romantismo" tiveram grande adesão por parte da historiografia proeminente, atribuindo menos dedicação e importância ao período de fato e suas particularidades do que aos outros mais notórios; segundo esta visão, romantismo e modernismo de 22. Outras generalizações correm em paralelo com estas atribuições. A título de exemplo, sobre a intelectualidade de 22, segundo Carpeaux: "Não Ihe precedeu nenhum 'modernismo'

5 São Paulo, após, sobretudo, a campanha civilista em 1910, passa a pleitear uma identidade paulista que resumiria a identidade nacional (SALIBA, 2004, p. 580). 
à maneira hispano-americana, pré-simbolista ou simbolista, mas só um parnasianismo acadêmico, de vida artificialmente prolongada, literatura sem raízes na vida da nação". Restava aos verdadeiros modernistas brasileiros somente, ainda segundo o crítico, "criar uma nova poesia e arte realmente nacionais, brasileiras, e empregar, para tanto, os recursos das vanguardas europeias, da França e Itália" (CARPEAUX, 1966, pp. 3166-3167). Há, portanto, um corte temporal abrupto, um salto evolutivo necessário, na visão do crítico, de um "parnasianismo acadêmico" para, enfim, a redenção propagada por "uma nova poesia e arte realmente nacionais". A Semana de 22 parece se gestar sozinha, sem rastros ou laços com o passado, o qual pode ser abreviado apenas por uma única tendência estética, a parnasiana. De modo geral, obras críticas que abarcam grande contingente de autores e até nações, como é caso de Literatura Ocidental, da qual foi retirado o excerto acima, replicam discursos tão gerais quanto seletivos, assumindo, às escondidas, processos de ofuscamento de expressões artísticas importantes e de gêneros considerados secundários, como todos aqueles que derivam da relação entre jornalismo e literatura. Trabalham, a rigor, a exposição do cânone, já digerido por um caminho previamente estabelecido de leitura; o que talvez explique a proporcionalidade entre sua abordagem ampla e sua adesão passiva, como se a obra tratasse de temas e métodos irrefutáveis.

O primeiro exercício necessário consiste, talvez, em reconhecer algumas distinções entre vanguarda e modernismo, sem, no entanto, polarizar tais categorias, sob

pena de incorrer nos mesmos apontamentos acima. Afinal de contas, processam, cada qual à sua maneira, sintomas da modernidade. Este raciocínio permite uma ampliação da noção de modernismo no Brasil, de modo que não se atém à linha evolutiva, cujo ponto alto está em 22, em virtude de uma percepção ramificada e polivalente, abrindo caminho para a relação entre literatura e jornalismo.

Em países da América Latina ou mesmo França e Estados Unidos, à apreensão modernista combinam-se conteúdos que ultrapassam sentidos estéticos tão sólidos. Dentre as mais variadas tentativas de definição conceitual, sublinho as investidas do crítico Marshall Berman, que, embora não encerre muitas questões importantes, levanta hipóteses sobre as quais poderemos nos debruçar de modo mais específico para erigir o contexto literário em questão. No que toca à diferenciação entre vanguarda e modernismo, como compreendemos a comparação que o estudioso faz entre as respostas à modernidade no século XIX e 
XX, sua obra intitulada Tudo que é sólido desmancha no ar, publicada no início da década de 1980, sugere uma inflexão determinante entre ambas as esferas:

Nossos pensadores do século XIX eram simultaneamente entusiastas e inimigos da vida moderna, lutando desesperados contra suas ambiguidades e contradições; sua auto-ironia e suas tensões íntimas constituíam as fontes primárias de seu poder criativo. Seus sucessores do século XX resvalaram para longe, na direção rígida de polarizações e totalizações achatadas. A modernidade ou é vista com um entusiasmo cego e crítico ou é condenada segundo uma atitude de distanciamento e indiferença neo-olímpica; em qualquer caso, é sempre concebida como um monólito fechado, que não pode ser moldado ou transformado pelo homem moderno. Visões abertas da vida moderna foram suplantadas por visões fechadas: Isto e Aquilo substituídos por Isto ou Aquilo. (BERMAN, 2007, p. 35)

A produção intelectual do século XIX, no contexto do crítico, guarda algumas características importantes: simultaneidade; ambiguidade; contradição. Por outro lado, os sucessores do século XX: rigidez; polarização; totalização. Esta análise reserva faces díspares da modernidade. Da primeira perspectiva sobressai um ecletismo natural, convívio de sensos discrepantes, capacidade de absorção do contraditório e da coexistência de pontos de vista em um mesmo núcleo, ou seja, "Isto e Aquilo". A segunda perspectiva é radical, fracionada em polos de tensão organizados por um pendor auto afirmativo, sempre em oposição a um outro projetado, ou seja, "Isto ou Aquilo". No limite, é uma tentativa sutil de diferenciação de modernistas e vanguardistas. À luz de tal discussão, outro importante teórico reforça em algum grau esta orientação ao dizer que o "modernismo havia proposto um novo tipo de arte para um novo tipo de mundo social e perceptivo." Ao passo que a vanguarda "via-se como desbravadora do futuro: seus membros não eram os portadores do progresso já repetidamente definido, mas os militantes de uma criatividade que reviveria e libertaria a humanidade" (WILLIAMS, 2011, p. 30). Assim, grosso modo, os modernistas respondiam a uma dada realidade volúvel, enquanto os vanguardistas, mais pretensiosos, seriam, em perspectiva póstera, a própria resposta.

Pois bem, no Brasil os chamados "pré-modernistas", termo problemático, podem equivaler em alguma ordem aos "pensadores do século XIX", modernistas, explicitados por Berman, uma vez que conservam um espírito paradoxal e ambí- 
guo, "Isto e aquilo". Por consequência, seguindo o raciocínio, apresentam novidade artística (premida largamente pela produção jornalística) para um cenário igualmente novo, se emprestarmos as palavras de Williams. Em alternativa, os modernistas de 22, seguindo o roteiro, estariam para os "pensadores do século XX", vanguardistas, pois polarizam os modos de percepção em um ímpeto exclusivista, "Isto ou aquilo". Autodenominam-se: são militantes pioneiros em busca de redenção, via criatividade, de um falso passado. A crítica brasileira, portanto, tendeu mais a assumir o rompimento com o passado literário tal e qual proposto pelos modernistas da Semana, prejudicando, inclusive, a apreensão da trajetória intelectual daqueles que compuseram o próprio evento de 22 , destacando-os do contexto literário e elegendo-os exclusivos, na medida em que estes também atuaram intensamente nos jornais antes e depois desta data, carecendo de trabalhos que perscrutem esta inclinação. ${ }^{6}$ A dificuldade em reivindicar o jornal como fonte literária é a dificuldade de admitir a heterogeneidade das formas, dos discursos, dos projetos literários em curso simultaneamente (exitosos ou não) enquanto caráter constitutivo e indispensável para apreensão dos signos próprios da modernidade literária brasileira e seu itinerário.

Com efeito, essas aproximações servem menos para propor novos critérios classificatórios do que para expor as fragilidades das categorias sobre as quais a crítica brasileira tem se apoiado no trato literário da época. Portanto, tomemos a heterogeneidade do período, calcada especialmente nas relações entre imprensa e literatura, como fator legítimo, passível de interpretação sob a ótica moderna, em seu sentido amplificado, portadora de estética própria, e não mais como simples período intervalar que prepara terreno para os que virão em seguida.

6 Vale destacar alguns trabalhos que, ou por elaborar edições ou por tratar da produção jornalística dos escritores modernistas da Semana, contradizem tal tendência da crítica, muito embora não revelem as produções dos escritores fora do panteão de 22, igualmente importantes: Tarsila Cronista, de Aracy Amaral, 1975; Menotti Del Picchia: o gedeão do modernismo: 1920-22, de Yoshie Sakiyama Barreirinhas, 1983; Palcos em foco: crítica de espetáculos, ensaios sobre teatro (1923-1933) - tentativas no campo da dramaturgia, de Cecília Lara, 2009 (sobre Antônio Alcântara Machado); Cinematographos- antologia da crítica cinematográfica, com organização de Donny Correia e Marcelo Tápia, 2016 (sobre Guilherme de Almeida) e os diversos estudos que tratam das produções jornalísticas de Mário de Andrade feitos por Therezinha Apparecida Porto Ancona Lopez. 


\section{Referências}

BERMAN, Marshall. Tudo que é sólido desmancha no ar: a aventura da modernidade. São Paulo: Companhia das Letras, 2007.

CARPEAUX, Otto Maria. As revoltas Modernistas. In História da literatura ocidental. Rio de Janeiro: O Cruzeiro, 1966.

CARVALHO, José Murilo de et al. Sobre o pré-modernismo. Rio de Janeiro: Fundação Casa de Rui Barbosa, 1988.

COHEN, Ilka Stern. Diversificação e segmentação dos impressos. In MARTINS, A.; LUCA, T. (orgs.). História da Imprensa no Brasil. São Paulo: Contexto, 2011, p. 103-130.

HALLEWELL, Laurence. O livro no Brasil: sua história. São Paulo: Edusp, 2012.

FAUSTO, Boris. Trabalho urbano e conflito social: 1890-1920. São Paulo: Companhia das Letras, 2016.

MARTINS, Ana Luiza. Imprensa em Tempos de Império. In MARTINS, A.; LUCA, T. (orgs.). História da Imprensa no Brasil. São Paulo: Contexto, 2011, p. 45-80.

MELO, José Marques de. Sociologia da Imprensa Brasileira: a implantação. Petrópolis: Vozes, 1973

RAMOS, Julio. Desencuentros de la Modernidad en América Latina: literatura y política en el siglo XIX. Caracas: Fundación Editorial El Perro y la Rana, 2009.

RIO, João do. $O$ momento literário. Rio de Janeiro: Fundação Biblioteca Nacional, Dep. Nacional do Livro, [1905] 1994.

SAES, Flávio. São Paulo republicana: vida econômica. In História da Cidade de São Paulo, v. 3: a cidade na primeira metade do século XX. PORTA, P. (org.). São Paulo: Paz e Terra, 2004, p. 215-258.

SALIBA, Elias Thomé. Aventuras e desventuras de José Agudo, um cronista da Pauliceia na belle époque. Revista USP / USP, n. 63, p. 102-109, 2004. Disponível em: http:// www.revistas.usp.br/revusp/article/view/13371. Acesso em 10 mar 2018.

SALIBA, Elias Thomé. Histórias, memórias, tramas e dramas da identidade paulistana. In PORTA. P. (org). História da Cidade de São Paulo, v. 3: a cidade na primeira metade do século XX. São Paulo: Paz e Terra, 2004, p. 555-588.

SEVCENKO, Nicolau. Literatura como missão: tensões sociais e criação cultural na Primeira República. São Paulo: Brasiliense, 1983.

SOARES, Órris. Elogio de Augusto dos Anjos. In Augusto dos Anjos - Obra Completa. Rio de Janeiro: Nova Aguilar, 2004.

SODRÉ, Nelson Werneck. História da Imprensa no Brasil. São Paulo: Martins Fontes, 1983.

WILLIANS, Raymond. Política do modernismo: contra os novos conformistas. São Paulo: Editora da Unesp, 2011. 